\title{
The Effect of Process Parameters on the Microstructure and Mechanical Performance of Fiber Laser-Welded AA5182 Aluminium Alloys
}

\author{
Celalettin Yuce , $^{*}$ - Mumin Tutar ${ }^{1}$ - Fatih Karpat ${ }^{1}$ - Nurettin Yavuz ${ }^{1}$ - Gökhan Tekin ${ }^{2}$ \\ 1 Uludag University, Department of Mechanical Engineering, Turkey \\ 2 Coskunöz A.Ş., Turkey
}

The laser welding of aluminium alloys is an important industrial technology but many challenges remain. The objective of this research is to investigate the effect of laser welding parameters on the quality of the fiber laser lap welded AA5182 aluminium alloy. The influences of the laser power, welding speed and focal point position on the mechanical and microhardness properties of the joints were experimentally investigated. The mechanical properties of the joints were evaluated by performing tensile tests. From the experimental results, optimum process parameters were determined, and microstructural examination and microhardness tests were conducted to better understand the performance of the joints. It was found that there is a correlation between the tensile shear loads of the joints and heat input per unit length. At the optimized parameters, the welded joint showed good weld appearance without macro defects, and the joint had an adequate tensile shear load.

Keywords: fiber laser welding, aluminium alloys, mechanical characterization, microstructural analysis

\begin{abstract}
Highlights
- $\quad$ Laser power has an increasing effect on the tensile shear load of the joints to a certain value.

- $\quad$ The highest tensile load was obtained for 2750 W laser power, $20 \mathrm{~mm} / \mathrm{s}$ welding speed, and a 100-mm focal point position.

- In the fusion zone of the optimum sample, nearly $12 \%$ magnesium loss and some interdendritic shrinkage cavities were detected.

- $\quad$ The fusion zone (FZ) of the sample which has a highest tensile shear load, mostly consists of columnar dendritic microstructure and could be divided into two different zones as internal FZ and external FZ.
\end{abstract}

\section{O INTRODUCTION}

The growing demand for more fuel-efficient vehicles to reduce energy consumption and air pollution is a challenge for the transport industry. Aluminium is a key material for lightweight structures in vehicles. It allows a mass saving of up to $50 \%$ over competing materials in most applications without compromising safety [1]. Furthermore, aluminium has many advantageous properties, e.g. low density, high strength, excellent formability, good corrosion resistance and recycling potential.

Welding is one of the essential processes for vehicle body manufacturing. Selecting the appropriate welding method is necessary to obtain a proper performance of the welded joint. Over the previous two decades, with the wide application of aluminium alloys in automotive, aerospace and other industries, laser welding has become critical joining method. With its high process speeds, single-sided access, no direct tool contact with the workpiece, and being amenable robotic automation, it proved to be an ideal assembly technology for car body fabrication [2]. In comparison to other conventional welding processes, laser welding offers the benefit of a narrow heat- affected zone that helps to minimize metallurgical problems [3]. Although aluminium alloys have many advantages, there are some problems are encountered with welding these alloys [4]. The wide range of temperatures in vaporization and solidification can lead to keyhole instability, blowholes, porosity and various defects in the welding metallurgy, such as hot cracking [5]. The loss of alloying elements is another problem Furthermore, there is a poor coupling of the laser energy due in part to the high density of free electrons in the solid, making aluminium one of the best reflectors of light [6].

These problems from the welding aluminium alloys and mechanical properties of the joints are directly influenced by process parameters; the effect of these parameters on the weld quality was investigated by several researchers in the literature. SanchezAmaya et al. [6] investigated laser welded 5083 and 6082 aluminium alloys under conduction mode and found that welding speed was more influential than laser power on the final size of the weld bead. Yang et al. [7] examined the effect of the incident beam position, incident beam angle and beam separation distance on weld quality. The results indicated that weld penetration was increased significantly as the 
incident beam angle increased. Ancona et al [8] conducted laser butt welding of AA5083 aluminium alloy. They used the design of the experiment technique to investigate the effects of the variables on the mechanical properties and porosity level and stated that in terms of tensile load the best results were found for high powers and high welding speeds. Kim et al. [9] investigated the effects of the parameters on the AA5052 aluminium alloy weldability. They indicated that the bead quality was improved when the beam was defocused in comparison to focus on the material surface position. Wang et al. [10] reported the effect of different beam oscillating pattern on the weld characterization of aluminium alloys. They indicated that beam oscillation has no effect on weld strength but an obvious effect on elongation.

Katayama et al. [11] investigated the effect of process parameters on the penetration and defect formation of the bead on plate welded AA5083 aluminium alloys. They reported that the weld beads were narrower and deeper with an increase in the power density. El-Batahgy and Kutsuna [12] clarified the effect of welding parameters on the porosity level and solidification cracking and they found that the tendencies for porosity and solidification cracking were increased at high welding speed conditions. Chang et al. [13] showed that the welding defect rate of the pulsed wave type was larger than that of the continuous type, and the crack rate was reduced with decreasing welding speed. Kim and Park [14] investigated the effect of the process variables on the tensile strength of the laser welded $5 \mathrm{~J} 32$ aluminium alloy. Wang et al. [15] stated that the solidification duration of the molten pool is the key factor for porosity. Zhang et al. [16] evaluated the microstructural and mechanical properties of the laser welded new type of $\mathrm{Al}-\mathrm{Zn}-\mathrm{Mg}-\mathrm{Cu}$ alloy sheets. They stated that the ultimate tensile strength of the joint was $69.7 \%$ of that of the base material tensile strength and those samples of the tensile tests were always fractured at the weld bead. Yang et al. [17] investigated the application of dual-beam laser in the conduction welding mode for aluminium panels in a coach-peel joint configuration. They stated that cross-beam laser joined parts provided the best weld surface quality.

In recent decades, the laser welding of aluminium alloys has attracted more attention owing to its remarkable advantages over other joining processes. Many experimental and theoretical studies have been made to understand the laser welding phenomenon in several industries [18] to [20]. However, there is still a lack of information about the effect of fiber laser welding process parameters on the microstructural and mechanical properties of materials with large heat conductivity or with volatile chemical elements, such as the $5 \mathrm{xxx}$ series. For these alloys, proper welding parameter range is usually narrow and difficult to be found because the keyhole and weld pool may violently fluctuate in the welding process [21]. In the present study, laser lap welding was performed with AA5182 aluminium alloy in order to conduct basic investigations into the effects of welding process parameters on the mechanical and microstructural properties of the joints. The process parameters considered in the experiments were the laser power, welding speed, and focal point position. The weldability evaluation used microstructural and microhardness examination of the cross section, and tensile tests to express the mechanical properties.

\section{MATERIALS AND METHOD}

The present study was performed on rolled sheets of AA5182 aluminium alloy with a thickness of $2 \mathrm{~mm}$. Its chemical composition is shown in Table 1. AA5182 alloy is an important commercial aluminium alloy with high strength, high ductility, high corrosion resistance, and good formability. It has been widely used for the manufacturing of automobile components. In recent years, it has also been considered for car body sheets.

Table 1. Chemical composition of AA5182 alloy

\begin{tabular}{lcccccc}
\hline Element & $\mathrm{Si}$ & $\mathrm{Fe}$ & $\mathrm{Mn}$ & $\mathrm{Mg}$ & $\mathrm{Cu}$ & $\mathrm{Zn}$ \\
\hline [wt \%] & 0.2 & 0.3 & 0.4 & 4.5 & 0.1 & 0.25 \\
\hline
\end{tabular}

The dimensions of each sheet were $140 \mathrm{~mm}$ in length, $140 \mathrm{~mm}$ in width, and $2 \mathrm{~mm}$ in thickness. The gap between two sheets was kept tight during welding. Before welding strict chemical cleaning was applied to the welded surfaces in order to reduce possible oxide film and other residues. The configuration and geometry of overlap joint and clamped welding sample are shown in Figs. 1a and b.

Welds were made using an IPG Ytterbium fiber laser system (YLS - 3000) attached to a Kuka robotic arm. The maximum average power of the laser was $3000 \mathrm{~W}$ of the continuous laser with $1070 \mathrm{~nm}$ wavelength. During the welding, the incident angle of the laser was fixed at $6^{\circ}$ (i.e. forward inclination) to prevent damage to the optics due to back reflection. Helium was utilized as a shielding gas with a flow rate of $11 \mathrm{l} / \mathrm{min}$ from a side nozzle angle at $45^{\circ}$ directed forward. The process variables of this study were laser power, welding speed, and focal point position. At a focal point position of $100 \mathrm{~mm}$ laser beam is focused 


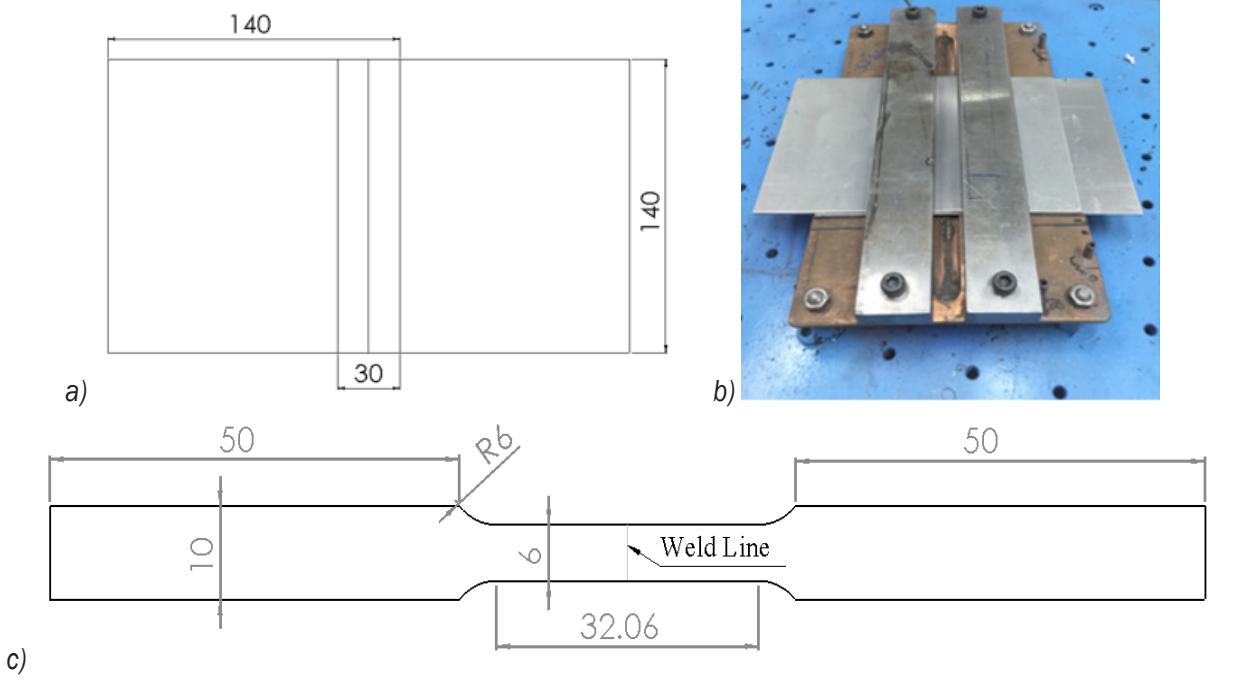

Fig. 1. a) Geometry of laser welded lap joint, b) clamped sample, and c) dimension of the tensile test specimen

on the top sheet surface. Welding conditions and levels of the process variables are shown in Table 2. The levels of the process parameters were chosen based on previous studies in the literature and pilot experiments were carried out to determine the practical operating range of each individually selected process parameters in order to produce a weld of acceptable quality.

For the metallographic characterization and microhardness measurement, the welded joints were cross-sectioned through the weld bead centre, using an electrical-discharge cutting machine. The crosssectioned samples were mounted in Bakelite, then ground and polished successively with a $1 \mu \mathrm{m}$ and $0.3 \mu \mathrm{m} \mathrm{Al}{ }_{2} \mathrm{O}_{3}$ suspension, respectively. Two different etching procedures were conducted to reveal the grain boundaries and weld zone microstructure. The first of these was $0.5 \mathrm{ml} \mathrm{HF}$ in $100 \mathrm{ml} \mathrm{H}_{2} \mathrm{O}$ solution. To reveal some microstructures, subsequently, polished specimens were tint etched using Weck's reagent which consists of $100 \mathrm{ml} \mathrm{H}_{2} \mathrm{O}, 4 \mathrm{~g} \mathrm{KMnO}_{4}$, and $1 \mathrm{~g} \mathrm{NaOH}$. Then, etched samples were analysed for microstructural changes, atomic percent of the alloying elements and possible defects using a Nikon DIC optic microscope (OM) with a Clemex image analysis system and Zeiss EVO 40 XVP scanning electron microscope (SEM) complemented by energy-dispersive spectroscopy (EDS). Vickers microhardness measurements were performed on a DUROLINE-M microhardness tester using a diamond pyramid indenter with a 50-g load, and 10 $\mathrm{s}$ dwell time; five readings were taken from which the average was determined. To determine the tensile shear load of the laser welded joints, the test samples were prepared based on the ASTM-E8 standards (Fig. 1c). Tensile shear tests were performed using a fully computerized UTEST-7014 tensile testing machine at room temperature using a constant crosshead speed of $5 \mathrm{~mm} / \mathrm{min}$.

\section{RESULTS AND DISCUSSION}

\subsection{Effect of Process Parameters on the Tensile Shear Load}

The major welding parameters that affect the quality of laser welded joints are laser power, welding speed, and focal point position. Compared with steel, due to the $\mathrm{Al}$ alloys having higher initial reflectivity to laser beams and greater thermal conductivity, greater power densities are needed to achieve keyhole welding. Therefore, laser power, spot size, and the welding speed are important variables for the welding process. All the average tensile test results for the different process variables were reported in Table 2. An average of four test results of the tensile load (TL) was calculated for each sample and the maximum standard deviation was 0.20 .

The effect of the laser power of $2.25 \mathrm{~kW}, 2.5 \mathrm{~kW}$, $2.75 \mathrm{~kW}$ and $3 \mathrm{~kW}$ on the tensile load of the joint was investigated at a constant welding speed of $20 \mathrm{~mm} / \mathrm{s}$ and $100 \mathrm{~mm}$ focal point position. Tensile test results were shown in Fig. 2. As shown in the results, laser power has a positive effect on the tensile shear load of the joints to a certain value. With increasing laser power after $2.75 \mathrm{~kW}$ at a constant welding speed $(20$ 
$\mathrm{mm} / \mathrm{s}$ ) tensile load of the joint was decreased. When the laser power was too high, excessive heat input caused excessive penetration and evaporation of the weld bead; therefore, the tensile load of the joints was decreased. However, if the laser power was too low, the coupling of laser energy to workpiece and penetration may be lost. A decrease in the depth of penetration was observed as the heat input decreased due to the low laser power levels. Thus, the tensile load of the weld was decreased. Therefore, to obtain a maximum tensile load, both laser power and heat input per unit length should be at a certain level. In this study, the maximum tensile load was obtained at the laser power of $2.75 \mathrm{~kW}$ at a constant welding speed of $20 \mathrm{~mm} / \mathrm{s}$ and focal point position of $100 \mathrm{~mm}$.

Table 2. Parameter combinations and average tensile test results

\begin{tabular}{cccc}
\hline $\begin{array}{c}\text { Laser power } \\
{[\mathrm{kW}]}\end{array}$ & $\begin{array}{c}\text { Welding speed } \\
{[\mathrm{mm} / \mathrm{s}]}\end{array}$ & $\begin{array}{c}\text { Focal point } \\
\text { position [mm] }\end{array}$ & $\begin{array}{c}\text { Avg. TL } \\
{[\mathrm{kN}]}\end{array}$ \\
\hline \multicolumn{5}{c}{ For constant laser power and focal position } \\
\hline 3 & 10 & 100 & 0.70 \\
\hline 3 & 20 & 100 & 1.53 \\
\hline 3 & 30 & 100 & 1.23 \\
\hline 3 & 40 & 100 & 1.08 \\
\hline \multicolumn{5}{c}{ For constant welding speed and focal position } \\
\hline 2.25 & 20 & 100 & 1.18 \\
\hline 2.5 & 20 & 100 & 1.30 \\
\hline 2.75 & 20 & 100 & 1.60 \\
\hline 3 & 20 & 100 & 1.53 \\
\hline \multicolumn{5}{c}{ For constant laser power and welding speed } \\
\hline 2.75 & 20 & 95 & 1.38 \\
\hline 2.75 & 20 & 100 & 1.60 \\
\hline 2.75 & 20 & 105 & 1.08 \\
\hline 2.75 & 20 & 110 & 0.96 \\
\hline \multicolumn{3}{c}{}
\end{tabular}

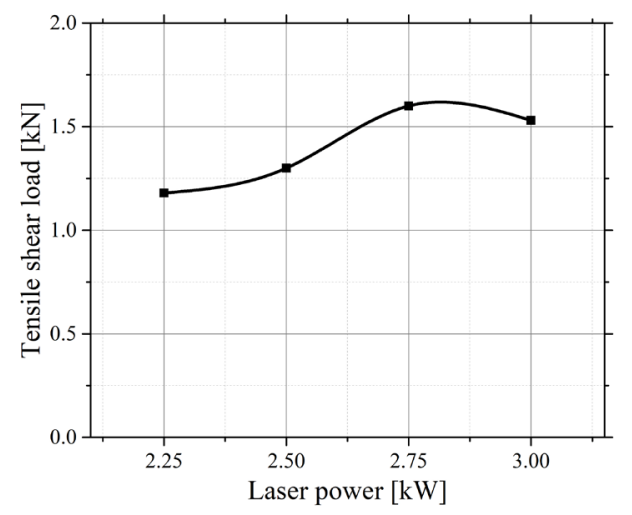

Fig. 2. Effect of laser power on TL of joints

The effect of four different welding speeds $(10 \mathrm{~mm} / \mathrm{s}, 20 \mathrm{~mm} / \mathrm{s}, 30 \mathrm{~mm} / \mathrm{s}$, and $40 \mathrm{~mm} / \mathrm{s})$ on the tensile load of the joint was investigated at a constant laser power of $3 \mathrm{~kW}$ and focal point position of 100 $\mathrm{mm}$. The results of tensile tests are shown in Fig. 3. As can be seen, tensile load values of the joints were relatively low at a welding speed of $10 \mathrm{~mm} / \mathrm{s}$. This is because too low a welding speed leads to excessive melting, loss of material, and weld perforation due to excessive heat input. At a constant laser power and the focal point position, the maximum tensile load was obtained at a welding speed of $20 \mathrm{~mm} / \mathrm{s}$. Because the penetration depth was inversely proportional to the welding speed for a given focal position and power, an increase in welding speed at constant power results in a corresponding decrease in penetration depth because of the reduction in the heat input [13]. Therefore, at welding speeds of $30 \mathrm{~mm} / \mathrm{s}$ and $40 \mathrm{~mm} / \mathrm{s}$, the tensile load of the joints was decreased.

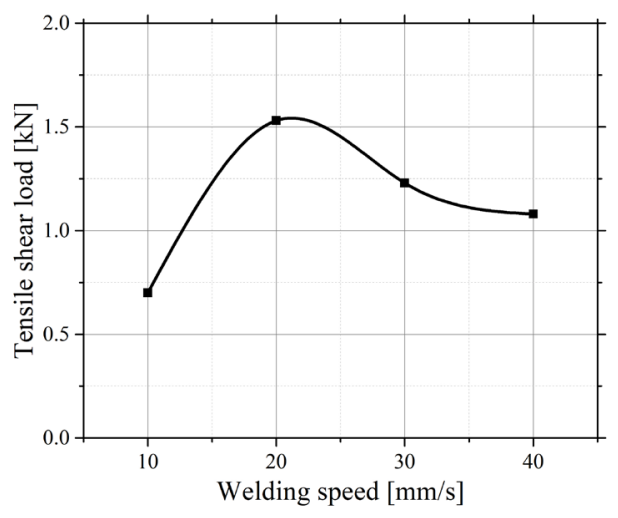

Fig. 3. Effect of welding speed on $T L$ of joints

Focal point position is the distance between the laser head and material surface. It determined the spot size and consequently the energy density on the sheet surface. The effect of focal point positions of $95 \mathrm{~mm}$, $100 \mathrm{~mm}, 105 \mathrm{~mm}$, and $110 \mathrm{~mm}$ on the tensile load of the joint was investigated at a constant welding speed of $20 \mathrm{~mm} / \mathrm{s}$ and laser power of $2.75 \mathrm{~kW}$. Tensile load results are shown in Fig. 4. When the focal point position was $100 \mathrm{~mm}$, the diameter of the laser spot was minimal. At this focal point position $(100 \mathrm{~mm})$, the laser beam was focused on the top aluminium sheet surface. Increasing or decreasing the point position resulted in the remarkable effect on the penetration depth and surface quality of the joints. When the focal point position was $100 \mathrm{~mm}$, the maximum penetration depth occurred. Therefore, the tensile load of this level was maximum. The focal position was $105 \mathrm{~mm}$ and $110 \mathrm{~mm}$ penetration depth was shallow. However, if the focal point position was too far below the sheet surface, in this case, $95 \mathrm{~mm}$, weld depth and weld width decreased, and the tensile load of the joint 
decreased. Furthermore, when the focal point position was too far above the sheet surface $(105 \mathrm{~mm}$ and 110 $\mathrm{mm}$ ) the diameter of the laser spot was increased and energy density on the surface was decreased [11]. Thus, penetration depth and tensile load decreased. According to the obtained experimental results, tensile load, penetration depth, and weld seam width were related to the process parameters. All the parameters and material properties and thicknesses should be considered when selecting the appropriate process parameters to obtain desired weld quality. It was found that penetration depth was related to the heat input so laser power and welding speed were determined properly. For complete penetration, using lower laser power with lower welding speed is required, but it is not acceptable from the view of productivity and the visual quality of the weld bead. Conversely, under increased welding speed and decreased laser power conditions, the heat input was decreased and full penetration did not occur. In terms of weld seam width, laser power was proportional to weld seam width. Weld seam width was increased as laser power increased. Welding speed affected the weld in the opposite way. Furthermore, focal point position influenced the weld width. The best performance was obtained for $2.75 \mathrm{~kW}$ laser power, $20 \mathrm{~mm} / \mathrm{s}$ welding speed and the $100-\mathrm{mm}$ focal point position.

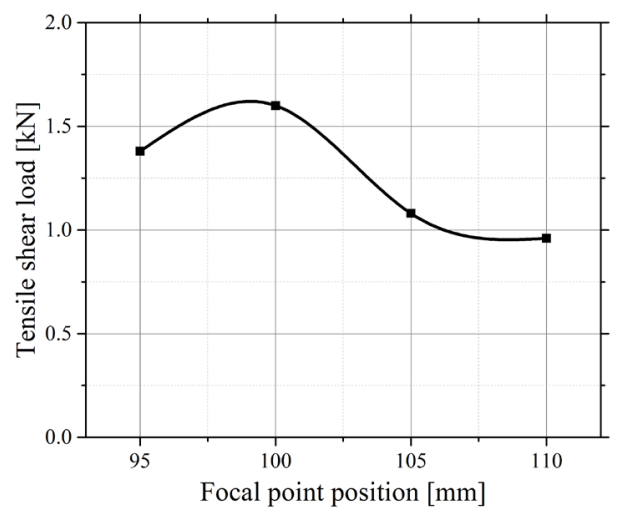

Fig. 4. Effect of focal position on TL of joints

\subsection{Microhardness and Microstructural Examination}

A selected sample, which has a maximum tensile load, was used for the evaluation of mechanical properties via microhardness measurement and microstructural examination using OM and SEM-EDS. Micrographs of the selected welded joint made using $2.75 \mathrm{~kW}$ laser power, $20 \mathrm{~mm} / \mathrm{s}$ welding speed, $100 \mathrm{~mm}$ focal point position are shown in Fig. 5.
Typically, three distinct zones were observed: the fusion zone (FZ), the heat-affected zone (HAZ), and base metal (BM). Although it was the sample showing best performance, in this sample, partial penetration was obtained. FZ mostly consists of columnar dendritic microstructures and could be divided into two different zones: internal FZ and external FZ.

With a narrow transition zone containing columnar and misoriented dendrites, the internal FZ is characterized by a fine precipitation of the second phases in a solid solution matrix of aluminium (Fig. 5a). External FZ showed a columnar dendritic structure due to a high cooling rate depending on the direction of heat flow (Fig. 5b). In addition, a few grain-sized HAZ were obtained near the fusion line (Fig. 5c).

The sample was also examined for possible defects. There was no crack in the FZ, however, some small defects were observed. The most discussed defect was hydrogen-related pores in the welding of aluminium alloys. Due to the deposition of supersaturated hydrogen in the weld pool, it was gathering and growing until finally it was too late for it to escape during the cooling process so it forms large regular circle-shaped pores with smooth walls, as can be seen in Fig. 6 a.

The pores could also form because of the surface contamination resulting from inadequate cleaning and shielding gas or engulfed metal vapor. Especially, in the keyhole regime conventional heat transfer between solid-liquid interface and collapse of liquid metal causes the occurrence of pores [22] and [23]. The optimum sample was also analysed with EDS. The analyses results showed that in the fusion zone nearly $12 \%$ magnesium loss was encountered, with respect to the BM. This finding is in good agreement with the studies in the literature [24] and [25]. It is believed that the pore in Fig. $6 \mathrm{~b}$ could be formed due to these reasons. Furthermore, some interdendritic shrinkage cavities have been detected.

In the SEM examination of the optimum sample, white particles were found in the fusion zone. They were considered to be iron-bearing particles. Additionally, it should be noted that some interdendritic cavities were found (Fig. 7a). The side surfaces of some cavities, shown with arrows, have a bright white layer (Fig. 7b). Due to the similarity of aswelded microstructure with as-cast microstructure and the presence of oxygen content in the FZ (confirmed with EDS analysis), these layers could be considered oxide layers [26] and [27]. Although shielding gas was used and pre-cleaning of the sheet surfaces was carried out, the presence of the oxides means that 

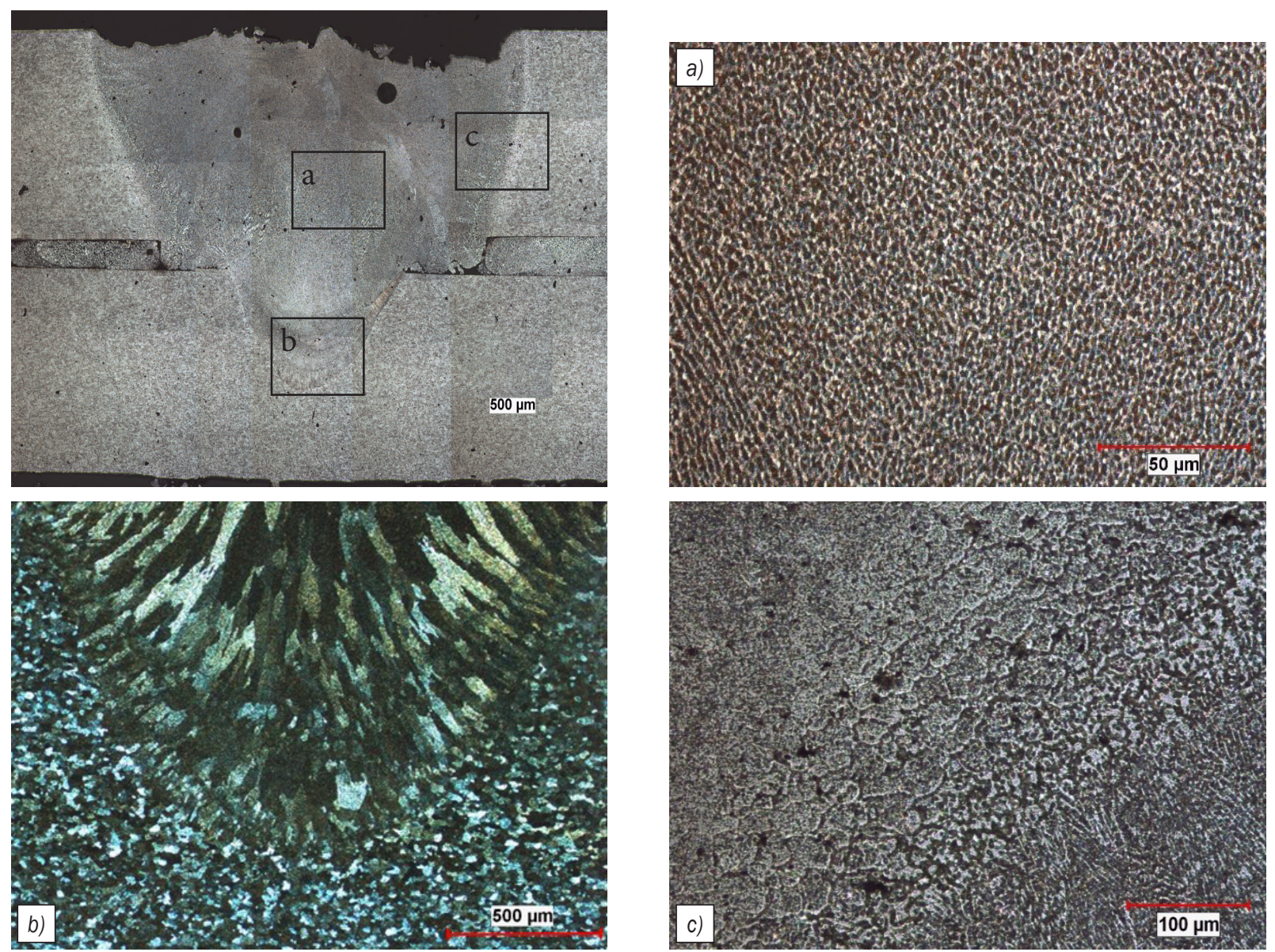

Fig. 5. Optical micrographs showing the optimum sample weld cross section, $F Z$ and $H A Z$ in detail: a) the internal $F Z$ b) the external $F Z$, and c) the edge of the $H A Z$
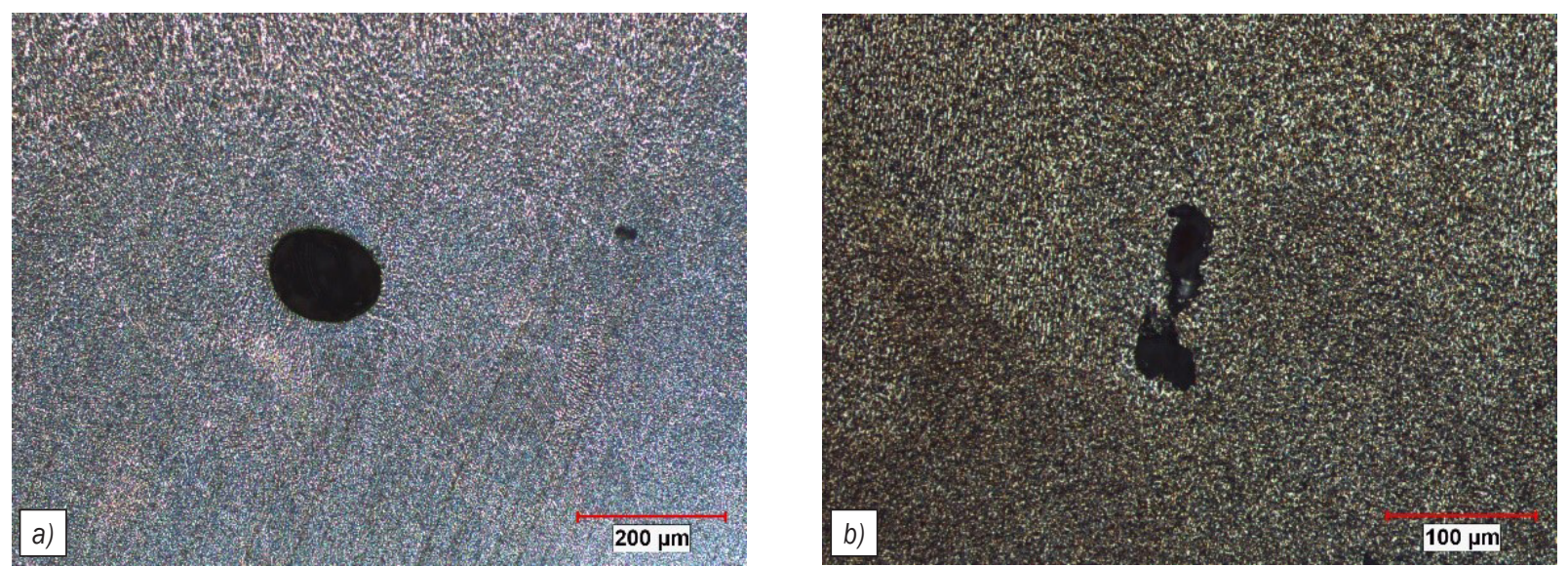

Fig. 6. Optical micrographs showing the defects in the FZ: a) Hydrogen related pore, and b) interdendritic shrinkage cavity

the shielding gas rate and/or pre-cleaning can be considered insufficient for the process parameters of the selected sample.

Microhardness tests were performed in order to characterize the weld-affected area, including
FZ (external and internal part), HAZ and the BM surrounding the bead. The microhardness map is shown in Fig. 8, measured on a cross-section according to ASTM E 384-99. Microhardness value of the BM was $83 \mathrm{HV}$. The hardness of the internal 

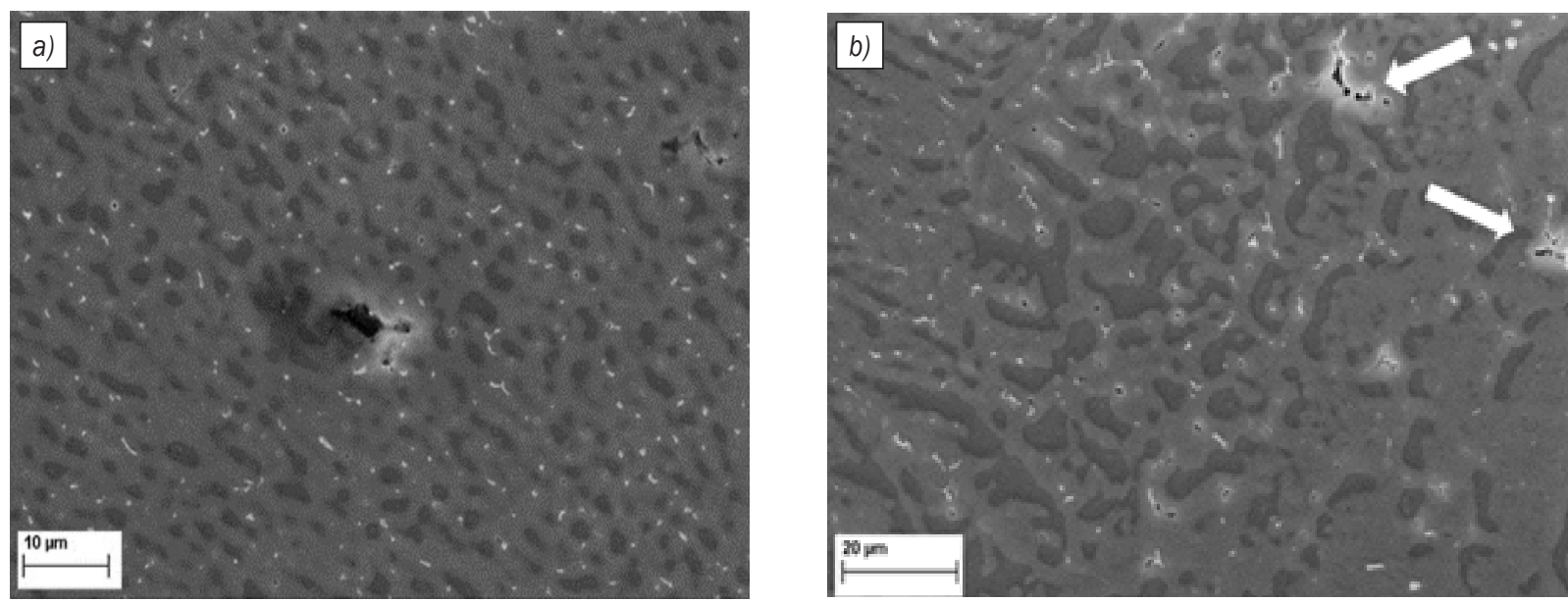

Fig. 7. SEM micrographs of: a) iron-bearing particles, and b) interdendritic cavity surfaces

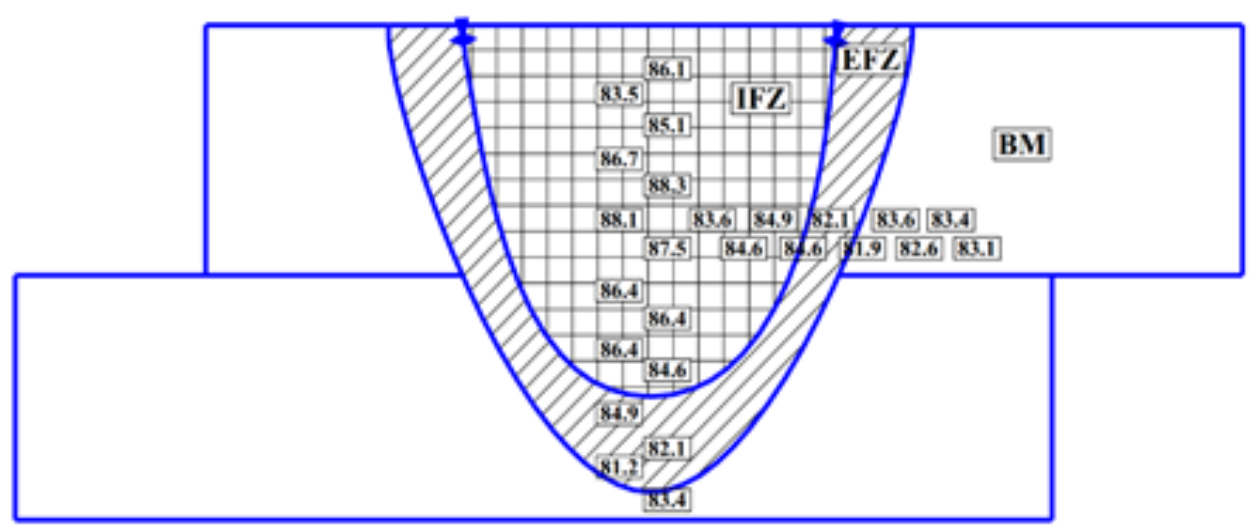

Fig. 8. Microhardness profiles of the optimum sample

FZ (IFZ) and external FZ (EFZ) are 86.8 HV and 83.5 $\mathrm{HV}$, respectively. As can be seen, the microhardness value of the FZ is slightly higher than that of the BM. The increase of the microhardness in the FZ has been reported by some researchers, especially in the nonheat treatable alloys with $O$ temper condition [6] and [25]. This is due to the microstructural refinement of the fusion zone with respect to the metal base. Since the width of the HAZ was smaller than the step size of microhardness measurement, the microhardness of the HAZ could not be measured clearly with the selected force. However, the hardness of the HAZ is roughly $82 \mathrm{HV}$.

\section{CONCLUSIONS}

In the present work, the fiber laser lap-welding experiments of AA5182 aluminium alloys were conducted. The effects of the laser power, welding speed and focal point position on the tensile load of the joints were investigated. Microstructural and microhardness examination of the optimum sample, which has the highest tensile load, was conducted.

According to the obtained experimental results, tensile load, penetration depth, and weld seam width were related to the process parameters. Concerning the tensile loads and bead profiles of the joints, it is observed that excessive heat input caused excessive penetration and evaporation of the weld bead so the tensile load of the joints was decreased. Conversely, insufficient heat input resulted in a decrease of the penetration depth, so tensile load was decreased. Therefore, heat input per unit length which depends on the laser power and welding speed should be selected carefully. Furthermore, experimental results showed that focal point position had an effect on the weld width and penetration depth. In this work, the highest tensile load was obtained for $2750 \mathrm{~W}$ laser power, $20 \mathrm{~mm} / \mathrm{s}$ welding speed, and $100 \mathrm{~mm}$ focal point position. 
The microstructural examination was conducted using OM, SEM, and EDS analyses. The microstructure of different zones of the optimum sample was examined. FZ mostly consists of columnar dendritic microstructures and could be divided into two different zones: internal FZ and external FZ. A few grain-sized HAZ were obtained in the vicinity of the fusion line. Small size defects were observed in the FZ. These were considered to be induced depositions of supersaturated hydrogen and interdendritic shrinkage cavities. As a result of the microhardness examination, due to the microstructural refinement of the fusion zone, hardness values were slightly increased in this zone. According to the EDS analysis in the fusion zone, nearly $12 \%$ magnesium loss encountered, with respect to the BM. Moreover, in the SEM examination, iron-bearing particles were found in the fusion zone.

\section{ACKNOWLEDGEMENTS}

The authors acknowledge the Uludag University Commission of Scientific Research Projects under Contract No. OUAP(MH)-2016/6 for supporting this research. And a part of this research was supported by the Coskunöz Holding Research and Development Department at Bursa, Turkey.

\section{REFERENCES}

[1] Hirsch, J. (2014). Recent development in aluminum for automotive applications. Transactions of Nonferrous Metals Society of China vol. 24, no. 7, 1995-2002, Dol:10.1016/ S1003-6326(14)63305-7.

[2] Rejc, J., Munih, M. (2016). Robust visual touch-up calibration method in robot laser spot welding application. Strojniški vestnik - Journal of Mechanical Engineering, vol. 62, no. 12, p. 697-708, D0I:10.5545/sv-jme.2016.3708.

[3] Pakdil, M., Cam, G., Kocak, M., Erim, S. (2011). Microstructural and mechanical characterization of laser beam welded AA6056 Al-alloy. Materials Science and Engineering A, vol. 528, no. 24, p. 7350-7356, D0l:10.1016/j.msea.2011.06.010.

[4] Cao, X., Wallece, W., Immarigeon, J.-P., Poon, C. (2007). Research and progress in laser welding of wrought aluminum alloys. II. Metallurgical microstructures, defects, and mechanical properties. Materials and Manufacturing Processes, vol. 18, no. 1, p. 23-49 D0l:10.1081/AMP120017587.

[5] Viscusi, A., Leitão, C., Rodrigues, D.M., Scherillo, F., Squillace, A., Carrinoa, L. (2016). Laser beam welded joints of dissimilar heat treatable aluminium alloys. Journal of Materials Processing Technology, vol. 236, p. 48-55, D0l:10.1016/j. jmatprotec.2016.05.006.

[6] Sánchez-Amaya, J.M., Delgado, T., González-Rovira, L., Botana, F.J. (2009). Laser welding of aluminium alloys 5083 and 6082 under conduction regime. Applied Surface Science, vol. 255, no. 23, p. 9512-9521, D0I:10.1016/J.apsusc.2009.07.081.

[7] Yang, Z.B., Tao, W., Li, L.Q., Chen, Y.B., Li, F.Z., Zhang, Y.L. (2012). Double-sided laser beam welded T-joints for aluminum aircraft fuselage panels: Process, microstructure, and mechanical properties. Materials \& Design, vol. 33, p. 652658, D0I:10.1016/j.matdes.2011.07.059.

[8] Ancona, A., Lugara, P.M., Sorgente, D., Tricarico, L. (2007). Mechanical characterization of $\mathrm{CO}_{2}$ laser beam butt welds of AA5083. Journal of Materials Processing Technology, vol. 191, no. 1-3, p. 381-384, D0I:10.1016/J.jmatprotec.2007.03.048.

[9] Kim, J.-K., Lim, H.-S., Cho, J.-H., Kim, C.-H. (2008). Weldability during the laser lap welding of Al 5052 sheets. Archives of Materials Science and Engineering, vol. 31, no. 2, p. 113-116.

[10] Wang, L., Gao, M., Zhang, C., Zeng, X. (2016). Effect of beam oscillating pattern on weld characterization of laser welding of AA6061-T6 aluminum alloy. Materials \& Design, vol. 108, p. 707-717, DOI:10.1016/J.matdes.2016.07.053.

[11] Katayama, S., Nagayama, H., Mizutani, M., Kawahito, Y. (2009). Fibre laser welding of aluminum alloy. Welding International, vol. 23, no. 10, p. 744-752, DOI:10.1080/09507110902836911.

[12] El-Batahgy, A., Kutsuna, M. (2009). Laser beam welding of AA5052, AA5083, and AA6061 aluminum alloys. Advances in Materials Science and Engineering, Article ID 974182, DOI:10.1155/2009/974182.

[13] Chang, C.C., Chou, C.P., Hsu, S.N., Hsiung, G.Y., Chen, J.R. (2010). Effect of laser welding on properties of dissimilar joint of Al-Mg-Si and Al-Mn aluminum alloys. Journal of Materials Science \& Technology, vol. 26, no.3, p. 276-282, D0l:10.1016/ S1005-0302(10)60046-1.

[14] Kim, D.Y., Park, Y.W. (2012). Weldability evaluation and tensile strength estimation model for aluminum alloy lap joint welding using hybrid system with laser and scanner head. Transactions of Nonferrous Metals Society of China, vol. 22, suppl. 3, p. 596-604, DOI:10.1016/S1003-6326(12)61771-3.

[15] Wang, J., Wang, G.Z., Wang, C.M. (2015). Mechanisms of the porosity formation during the fiber laser lap welding of aluminum alloy. Metalurgija, vol. 54, no. 4, p. 683-686.

[16] Zhang, L., Li, X., Nie, Z., Huang, H., Sun, J. (2015). Microstructure and mechanical properties of a new Al-ZnMg-Cu alloy joints welded by laser beam. Materials \& Design, vol. 83, p. 451-458, D0l:10.1016/j.matdes.2015.06.070.

[17] Yang, G., Ma, J., Carlson, B., Wang, H.P. Kovacevic, R. (2017). Effect of laser beam configuration on microstructure evolution and joint performance in laser joining AA 6111 panels. Materials \& Design, vol. 123, p. 197-210, D0I:10.1016/j. matdes.2017.03.050.

[18] Kim, S., Lee, W., Kim, D. (2015). One-step distortion simulation of pulsed laser welding with multi-physics information. International Journal of Simulation Modelling, vol. 14, no. 1, p. 85-97, DOl:10.2507/IJSIMM14(1)8.291.

[19] Shibib, K.S., Minshid, M.A., Tahir, M.M. (2009). Finite element analysis of spot laser of steel welding temperature history. Thermal Science, vol. 13, no. 4, p. 143-150, D0l:10.2298/ TSCI0904143S.

[20] Vegelj, D., Zajec, B., Gregorčič, P., Možina, J. (2014). Adaptive pulsed-laser welding of electrical laminations. Strojniški 
vestnik - Journal of Mechanical Engineering, vol. 60, no. 2, p. 106-114, DOI:10.5545/sv-jme.2013.1407.

[21] Pang, S., Chen, W., Zhou, J., Liao, D. (2015). Self-consistent modeling of keyhole and weld pool dynamics in tandem dual beam laser welding of aluminum alloy. Journal of Materials Processing Technology, vol. 217, p. 131-143, D0l:10.1016/j. jmatprotec.2014.11.013.

[22] Haboudou, A., Peyre, P., Vannes, A.B., Peix, G. (2003). Reduction of porosity content generated during Nd:YAG laser welding of A356 and AA5083 aluminium alloys. Materials Science and Engineering A, vol. 63, no. 1-2, p. 40-52, DOI:10.1016/S0921-5093(03)00637-3.

[23] Yang, J., Gang, S., Li, X., Chen, L., Xu, F. (2010). Typical joint defects in laser welding of Aluminium-Lithium alloy. Proceedings of the 36th International MATADOR Conference, p. 595-598, DOI:10.1007/978-1-84996-432-6_130.

[24] Sibillano, T., Ancona, A., Berardi, V., Schingaro, E., Basile, G., Lugarà, P.M. (2006). A study of the shielding gas influence on the laser beam welding of AA5083 aluminium alloys by in-process spectroscopic investigation. Optics and Lasers in Engineering, vol. 44, no. 10, p. 1039-1051, D0l:10.1016/j. optlaseng.2005.09.002.

[25] Sanchez-Amaya, J.M., Delgado, T., Damborenea, J., Lopez, V., Botana, F.J. (2009). Laser welding of AA 5083 samples by high power diode laser. Science and Technology of Welding and Joining, vol. 14, no, 1, p. 78-86, DOI:10.1179/136217108X347629.

[26] Li, Y.J., Arnberg, L. (2004). A eutectoid phase transformation for the primary intermetallic particle from $\mathrm{Alm}(\mathrm{Fe}, \mathrm{Mn})$ to $\mathrm{Al}(\mathrm{Fe}, \mathrm{Mn})$ in AA5182 alloy. Acta Materialia, vol. 52, no. 10, p. 2945-2952, D0I:10.1016/j.actamat.2004.02.041.

[27] Li, Y.J., Arnberg, L. (2004). Solidification structures and phase selection of iron-bearing eutectic particles in a DC-cast AA5182 alloy. Acta Materialia, vol. 52, no. 9, p. 2673-2681, D0I:10.1016/j.actamat.2004.02.015. 